\title{
SERUM VITAMIN D LEVELS IN DIABETICS AND ITS CORRELATION WITH DIABETIC RETINOPATHY
}

\author{
Anurag Chaurasia ${ }^{1}$, Sourabh Jain ${ }^{2}$
}

${ }^{1}$ Associate Professor, Department of Medicine, S. S. Medical College, Rewa, Madhya Pradesh.

${ }^{2}$ Senior Resident, Department of Medicine, S. S. Medical College, Rewa, Madhya Pradesh.

\section{ABSTRACT}

\section{BACKGROUND}

Diabetes mellitus continues to be a tremendous health burden in India. Diabetes is also the leading cause of new blindness in patients 20 to 74 years of age. Diabetics are 25 times more likely to become legally blind than Non-Diabetics. Vitamin D may play a role in the pathogenesis of diabetic retinopathy through its anti-inflammatory effect and calcitriol is a potent inhibitor of retinal neovascularisation in an oxygen-induced ischaemic retinopathy model. Given these associations, we sought to determine the relationship between vitamin D insufficiency and diabetic retinopathy.

Aims and Objectives- To estimate the serum Vitamin D levels in Diabetics and to establish the correlation between the serum Vitamin D levels and Diabetic Retinopathy.

\section{MATERIALS AND METHODS}

Diabetics either attending OPD or admitted in Department of Medicine, SGMH, Rewa, were assessed during Jul 2014 - Jun 2015. They were tested for HbA1c levels and serum Vitamin D and labelled insufficient for Vitamin D when serum levels were $<30$ $\mathrm{ng} / \mathrm{mL}$. They also underwent fundoscopic examination and were classified into No Background Diabetic Retinopathy (BDR), NonProliferative Diabetic Retinopathy (NPDR) of mild, moderate, severe and very severe grade and Proliferative Diabetic Retinopathy (PDR).

\section{RESULTS}

Diabetic subjects had lower Vitamin D levels than non-diabetic subjects $(20.7 \pm 6.91 \mathrm{ng} / \mathrm{mL}$ versus $27.51 \pm 5.53 \mathrm{ng} / \mathrm{mL}, \mathrm{p}<$ 0.0001). The mean Vitamin D levels were as follows: No diabetes or ocular disease- $28.90 \pm 4.70 \mathrm{ng} / \mathrm{mL}$, no diabetes with ocular disease- $25.60 \pm 6.12 \mathrm{ng} / \mathrm{mL}$, no BDR- $25.3 \pm 5.63 \mathrm{ng} / \mathrm{mL}$, NPDR (mild, moderate) $18.66 \pm 4.39 \mathrm{ng} / \mathrm{mL}$, NPDR (severe, very severe) PDR- $16.45 \pm 7.42 \mathrm{ng} / \mathrm{mL}$. Vitamin D levels demonstrated statistical significance between the body mass index, presence of Macrovascular disease, HbA1c and serum creatinine.

\section{CONCLUSION}

This study suggests that diabetic subjects, especially those with NPDR (severe and very severe grade) and PDR have lower Vitamin D levels than those without diabetes.

\section{KEYWORDS}

Diabetes Mellitus, Diabetic Retinopathy, Vitamin D.

HOW TO CITE THIS ARTICLE: Chaurasia A, Jain S. Serum vitamin D levels in diabetics and its correlation with diabetic retinopathy. J. Evolution Med. Dent. Sci. 2017;6(33):2735-2740, DOI: 10.14260/Jemds/2017/590

\section{BACKGROUND}

Diabetes mellitus is an "Iceberg disease." Diabetes mellitus is accepted as a worldwide epidemic with an estimated increase in prevalence from $2.8 \%$ in 2000 to $4.4 \%$ by 2030.1

The incidence of this disease continues to rise all over the world. Diabetes is recognised to be common in Asian Indians. The magnitude of problem is further compounded by various catastrophic microvascular and macrovascular complications targeting the vital organs in the body.

DM is the leading cause of blindness between the ages of 20 and 74. The gravity of this problem is highlighted by the finding that individuals with DM are 25 times more likely to become legally blind than individuals without DM. Blindness

Financial or Other, Competing Interest: None.

Submission 04-02-2017, Peer Review 12-04-2017,

Acceptance 18-04-2017, Published 24-04-2017.

Corresponding Author:

Dr. Sourabh Jain,

\#F-14/3, New Doctor's Colony,

Rewa- 486001.

E-mail: contactsourabh2002@yahoo.com

DOI: $10.14260 /$ jemds $/ 2017 / 590$ in Diabetes is primarily the result of progressive diabetic retinopathy and clinically significant macular oedema. While it has been well established that intensive blood glucose control can lower the risk of microvascular complications from diabetes, the pathophysiology of retinopathy progression is not completely understood. ${ }^{2-4}$

As of the current data, more than $50 \%$ of world's population is vitamin $\mathrm{D}$ insufficient. ${ }^{5}$ The pathogenesis of various diseases like cardiovascular, cancer, Alzheimer's disease, Parkinson's disease, etc. has shown the role of vitamin $\mathrm{D}$ insufficiency in the further development of disease.6,7

The anti-inflammatory effect of vitamin $\mathrm{D}$ is due to its anti-proliferative effects on lymphocytes, natural killer cells and reduction of a number of pro-inflammatory cytokines. ${ }^{10}$ Also, Calcitriol inhibits retinal neovascularisation as shown in some animal models. ${ }^{8}$ All these evidences provoked us to check the implication of vitamin D insufficiency in Diabetic Retinopathy.

\section{MATERIALS AND METHODS}

Type 2 Diabetic patients older than 18 years of age attending OPD and those admitted in Department of Medicine, S. S. 
Medical College and associated S. G. M. Hospital, Rewa (M. P.) from July 2014 to October 2015 were included in the study to minimise seasonal bias. Those with type 1 diabetes, younger than 18 years, taking vitamin D supplements, on medications such as Rifampicin and phenobarbital were excluded.

Patients were screened to determine their diabetes status, age, sex and addiction. Patients underwent routine ophthalmic examination including dilated fundoscopy and were included in the study if they were able to be matched into a study. Attempts were made to keep the study groups equally matched according to age (within 10 years) and sex. Once enrolled, completed a medical history questionnaire and had their blood tested for haemoglobin A1c, serum creatinine and 25-hydroxyvitamin D (25(OH)D). Haemoglobin $A_{1 c}$ levels were also measured using high performance liquid chromatography (HPLC). The 25(OH) vitamin D levels were measured from serum samples via an automated competitive immunoassay detected by chemiluminescence. The form of vitamin D measured is 25 $(\mathrm{OH})$ vitamin D total. It is a comparative study which included a total of 220 subjects which were divided into five distinct groups based on their diabetes status and retinopathy findings-

1. Subjects without Diabetes or any ocular disease.

2. Subjects without Diabetes but had some other form of ocular disease, such as uveitis or macular degeneration.

3. The no background diabetic retinopathy (No BDR) group consisted of subjects with type 2 diabetes, but no evidence of diabetic retinopathy.

4. Subjects in the Non-Proliferative Diabetic Retinopathy (NPDR) group had evidence of retinopathy, such as microaneurysms, cotton-wool spots, intraretinal haemorrhages or macular oedema, but no evidence of retinal or iris neovascularisation. This group included patients with mild-to-moderate NPDR.

5. The PDR group consisted of subjects with neovascularisation on the optic disc, retina or iris, with or without vitreous haemorrhage or prior panretinal photocoagulation. This group also included patients with severe to very severe NPDR.

Demographic variables were categorised as following: age was grouped by decades of life (18 to 39 years, 40 to 49 years, 50 to 59 years, 60 to 69 years, 70 to 90 years); and Body-Mass Index (BMI) was grouped as well (less than 25.0 $\mathrm{kg} / \mathrm{m} 2,25.1$ to $29.9 \mathrm{~kg} / \mathrm{m} 2,30.0$ to $34.9 \mathrm{~kg} / \mathrm{m} 2$ and greater than $35 \mathrm{~kg} / \mathrm{m} 2$ ). For those subjects with diabetes, duration of diabetes was categorised into groups (less than 5 years, 5 to 10 years, 10 to 15 years and greater than 15 years). Laboratory variables were grouped as following: haemoglobin A1c (less than 6.0, 6.0 to 6.9, 7.0 to $7.9,8.0$ to 8.9, 9.0 to 9.9 , greater than 10.0 ), and serum creatinine (less than $0.5 \mathrm{mg} / \mathrm{dL}, 0.5$ to $1.0 \mathrm{mg} / \mathrm{dL}, 1.0$ to $1.49 \mathrm{mg} / \mathrm{dL}, 1.50$ to $1.99 \mathrm{mg} / \mathrm{dL}$ and greater than $2.0 \mathrm{mg} / \mathrm{dL}$ ).

The presence of hypertension or macrovascular disease was also recorded. Subjects were considered to have macrovascular disease if they had ever been diagnosed with a myocardial infarction, cerebrovascular accident if they had undergone coronary artery bypass grafting surgery or a cardiac stenting procedure. Additionally, the duration of diabetes, which was defined as the interval between their diagnosis of type 2 diabetes and the time of their enrolment into this study and insulin usage was recorded for each diabetic patient.

\section{Fundus Photographs}

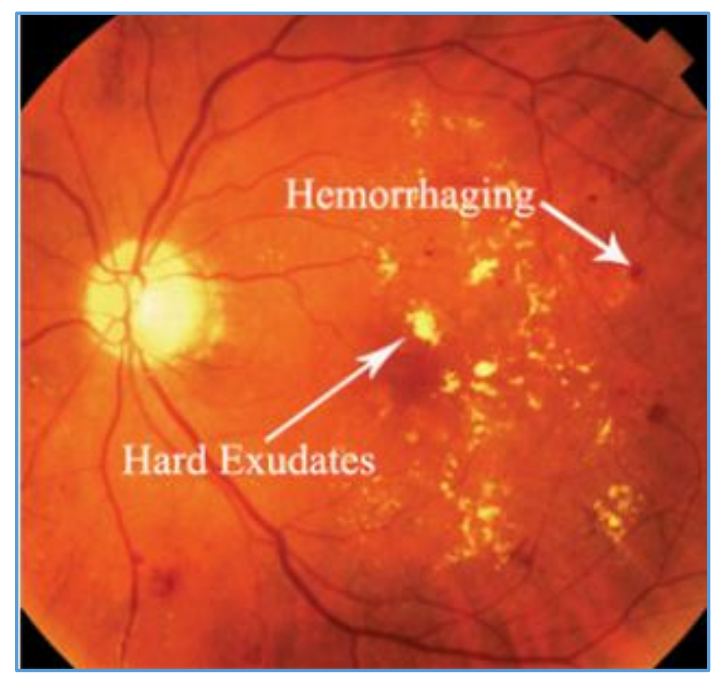

Mild NPDR

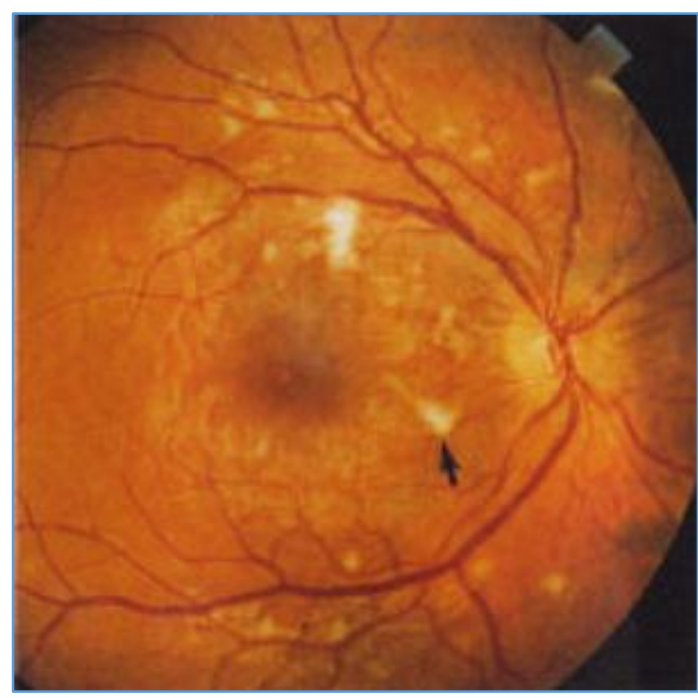

Moderate NPDR

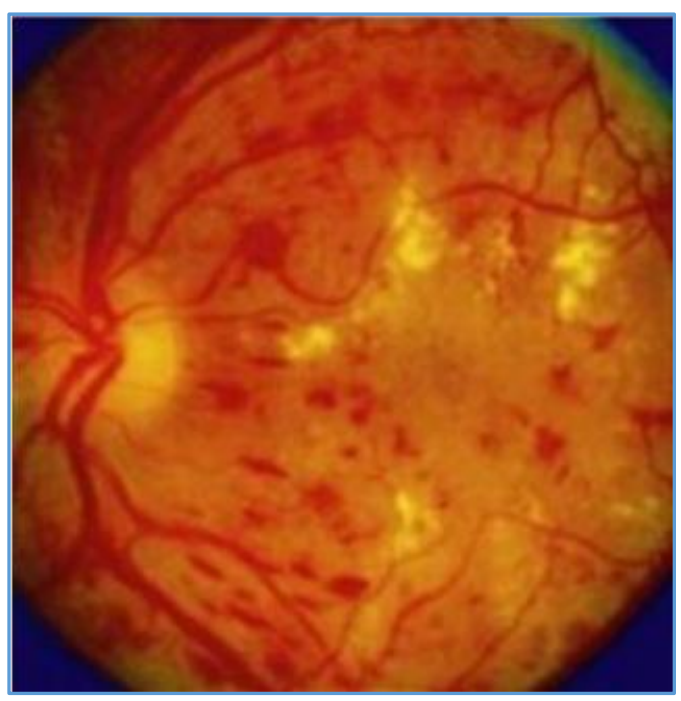

Severe NPDR 


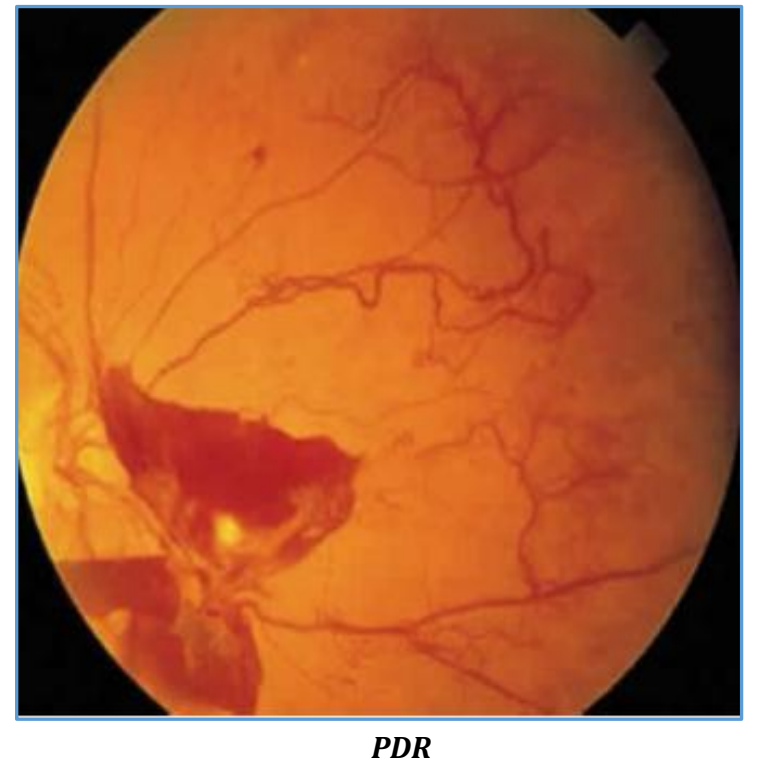

\section{Statistical Considerations}

One-way Analysis of Variance (ANOVA) and the chi-square test were used to compare the means and percentages for patient characteristics across study groups. One-way ANOVA was used to compare mean $25(\mathrm{OH})$ D across levels of patient characteristics. The mean $25(\mathrm{OH})$ D pair wise comparison between levels of the patient characteristics was tested using Tukey's multiple comparison procedure. Vitamin D was analysed as a dichotomous variable with a level less than 30 $\mathrm{ng} / \mathrm{mL}$ used to label insufficiency. Chi-square test was used to compare the percentages of subjects with vitamin D insufficiency across the various patient characteristics. All the statistical calculations were performed using SPAS and GraphPad InStat 3.

\section{RESULTS}

Subject characteristics in the 5 Study Groups and Vitamin D

The mean vitamin D levels are significantly lower in Diabetics as compared to Non-Diabetics in the age group 40 - 49 and age more than 70 years. The mean age in group with no background retinopathy is $49.6 \pm 11.28$ years, whereas in group with severe and very severe NPDR and PDR is $65.00 \pm$ 11.4 years and the difference in the age among the five groups is statistically significant $(p<0.0001)$.

The mean vitamin D levels were higher in females $(24.35$ $\pm 7.33 \mathrm{ng} / \mathrm{mL})$ as compared to males $(22.75 \pm 7.26 \mathrm{ng} / \mathrm{mL})$. But these results were statistically insignificant ( $p 0.116$ ). There is no significant difference in the distribution of male and female subjects in the 5 study groups ( $\mathrm{p}$ 0.43).

The mean vitamin D levels are significantly more $(\mathrm{p}<$ 0.0001 ) in patients with lesser BMI (mean vitamin D level of $28.23 \pm 3.24 \mathrm{ng} / \mathrm{mL}$ in $\mathrm{BMI}<20$ ) than those with higher BMI (mean vitamin D level of $19.73 \pm 8.15 \mathrm{ng} / \mathrm{mL}$ in $\mathrm{BMI}>30$ ) The BMI was significantly higher in those with higher grades of retinopathy. It is $23.52 \pm 3.70$ in no background retinopathy group and $26.37 \pm 3.43$ in those with severe very severe NPDR and PDR $(\mathrm{p}<0.0001)$.

\begin{tabular}{|c|c|c|c|c|}
\hline Characteristic & $\begin{array}{l}\text { Mean } \\
\text { Vit D }\end{array}$ & $P$ value & \begin{tabular}{|c|} 
Vit D \\
Insufficient (\%)
\end{tabular} & $\begin{array}{c}P \\
\text { value }\end{array}$ \\
\hline $\begin{array}{l}\text { Diabetics } \\
(\mathrm{n}=120)\end{array}$ & $\begin{array}{c}20.7 \pm \\
6.91\end{array}$ & \multirow{2}{*}{$\begin{array}{c}< \\
0.0001\end{array}$} & $91(110 / 120)$ & \multirow{2}{*}{$\begin{array}{c}< \\
0.0001\end{array}$} \\
\hline $\begin{array}{c}\text { Non-Diabetics } \\
(\mathrm{n}=100)\end{array}$ & $\begin{array}{c}27.51 \pm \\
5.53\end{array}$ & & $68(68 / 100)$ & \\
\hline
\end{tabular}

Table 1a. Mean Vitamin D Levels and \% age Insufficiency in Vitamin D among Diabetics and Non-Diabetics

The mean vitamin D level in Diabetics $(20.7 \pm 6.91$ $\mathrm{ng} / \mathrm{mL}$ ) is significantly less than that in non-diabetics $(27.51$ $\pm 5.53 \mathrm{ng} / \mathrm{mL})(\mathrm{p}<0.0001)$. Also, diabetics have significantly higher proportion of subjects with vitamin D insufficiency $(91.3 \%)$ as compared to Non-Diabetics (68\%).

\begin{tabular}{|c|c|c|c|c|}
\hline $\begin{array}{l}5 \text { Study } \\
\text { Groups }\end{array}$ & $\begin{array}{l}\text { Mean } \\
\text { Vit-D }\end{array}$ & $\begin{array}{c}\mathbf{P} \\
\text { value }\end{array}$ & $\begin{array}{c}\text { Vit-D } \\
\text { Insufficient } \\
(\%)\end{array}$ & $\begin{array}{c}P \\
\text { value }\end{array}$ \\
\hline $\begin{array}{c}\text { No DM no } \\
\text { ocular ds }(n=58)\end{array}$ & 28.90 & \multirow{5}{*}{$\begin{array}{c}< \\
0.0001\end{array}$} & $6(42 / 58)$ & \multirow{5}{*}{$\begin{array}{c}\chi^{2} 26.5 \\
p< \\
0.0001\end{array}$} \\
\hline $\begin{array}{c}\text { No DM with } \\
\text { Ocular ds (n = 42) }\end{array}$ & 25.60 & & $71 \%(30 / 42)$ & \\
\hline No BDR $(n=40)$ & $25.3 \pm 5.63$ & & 0) & \\
\hline $\begin{array}{l}\text { Mild - Mod NPDR } \\
\quad(\mathrm{n}=42)\end{array}$ & 18.66 & & $95 \%(40 / 42)$ & \\
\hline $\begin{array}{l}\text { SEV - V.SEV NPDR + } \\
\quad \text { PDR }(\mathrm{n}=38)\end{array}$ & $16.45 \pm 7.42$ & & $100(38 / 38)$ & \\
\hline \multicolumn{5}{|c|}{$\begin{array}{c}\text { Table 1b. Mean Vitamin D Levels and \% age Insufficiency } \\
\text { in Vitamin D in } 5 \text { Study Groups }\end{array}$} \\
\hline
\end{tabular}

The above table shows a significant and steady decline in mean serum vitamin D levels with increasing grades of Diabetic Retinopathy. The mean levels are $25.3 \pm 5.63 \mathrm{ng} / \mathrm{mL}$ in No Background Retinopathy Group, $18.66 \pm 4.39 \mathrm{ng} / \mathrm{mL}$ in group with mild-to-moderate NPDR and $16.45 \pm 7.42 \mathrm{ng} / \mathrm{mL}$ in severe and very severe NPDR and PDR. Also, the proportion of diabetics with vitamin D insufficiency is significantly more with increasing grades of Retinopathy.

\begin{tabular}{|c|c|c|c|c|}
\hline & $\begin{array}{c}\text { Mean } \\
25(O H) D \\
\text { Level }\end{array}$ & $P$ value & $\begin{array}{c}\text { Vitamin D } \\
\text { Insufficiency }\end{array}$ & P value \\
\hline \multicolumn{5}{|c|}{ Duration of Diabetes } \\
\hline $\begin{array}{c}<5 \\
(n=24)\end{array}$ & $22.86 \pm 6.01$ & \multirow{4}{*}{0.005} & $91.66(22 / 24)$ & \multirow{4}{*}{0.08} \\
\hline $\begin{array}{c}5-10 \\
(n=54)\end{array}$ & $20.77 \pm 6.28$ & & $88.89(48 / 54)$ & \\
\hline $\begin{array}{l}10-15 \\
(n=18)\end{array}$ & $17.56 \pm 3.44$ & & $100(18 / 18)$ & \\
\hline $\begin{array}{c}>15 \\
(n=40)\end{array}$ & $17.65 \pm 7.83$ & & $100(40 / 40)$ & \\
\hline \multicolumn{5}{|c|}{ Glycated Haemoglobin (HbA1c) } \\
\hline$<6$ & $28.08 \pm 4.75$ & \multirow{6}{*}{$<0.0001$} & $68.96(40 / 58)$ & \multirow{6}{*}{$<0.0001$} \\
\hline $6-6.9$ & $25.88 \pm 6.51$ & & $67.74(42 / 62)$ & \\
\hline $7-7.9$ & $22.80 \pm 5.78$ & & $92.85(26 / 28)$ & \\
\hline $8-8.9$ & $18.6 \pm 7.45$ & & $91.66(22 / 24)$ & \\
\hline $9-9.9$ & $17.81 \pm 7.02$ & & $100(24 / 24)$ & \\
\hline$>10$ & $17.52 \pm 6.49$ & & $100(22 / 22)$ & \\
\hline \multicolumn{5}{|c|}{ Insulin Usage } \\
\hline Yes & $17.40 \pm 7.54$ & \multirow{2}{*}{0.0006} & $90.47(38 / 42)$ & \multirow{2}{*}{0.79} \\
\hline No & $21.91 \pm 6.10$ & & $91.9(68 / 74)$ & \\
\hline \multicolumn{5}{|c|}{ Table 2a. Diabetic Profile and Vitamin D } \\
\hline
\end{tabular}


The mean vitamin D levels is significantly more ( $p$ 0.005) in subjects with lesser duration of Diabetes (mean vitamin D level of $22.86 \pm 7.10 \mathrm{ng} / \mathrm{dL}$ in less than 5 years' duration) as compared to those with longer duration of Diabetes (mean level of $17.65 \pm 6.98 \mathrm{ng} / \mathrm{dL}$ in more than 15 years' duration).

The mean vitamin $D$ levels are significantly more in subjects with lesser HbA1c levels $28.08 \pm 4.75 \mathrm{ng} / \mathrm{mL}$ in
HbA1c < 6) than those with higher HbA1c $(17.52 \pm 6.49$ $\mathrm{ng} / \mathrm{mL}$ in $\mathrm{HbA}_{1 \mathrm{c}}>10$ ). Also, proportion of subjects with vitamin $\mathrm{D}$ insufficiency is more those with higher $\mathrm{HbA} 1 \mathrm{c}$.

The mean vitamin D levels in Diabetics on Insulin therapy is significantly lower $(17.40 \pm 7.54 \mathrm{ng} / \mathrm{mL})$ than those on oral hypoglycaemics (p 0.0006).

\begin{tabular}{|c|c|c|c|c|c|c|}
\hline & $\begin{array}{c}\text { No Ocular DS } \\
\text { No DM } \\
(n=58)\end{array}$ & $\begin{array}{l}\text { No DM with } \\
\text { Ocular DS } \\
(n=42)\end{array}$ & $\begin{array}{l}\text { No BDR } \\
(n=40)\end{array}$ & $\begin{array}{l}\text { Mild-Mod } \\
\text { NPDR } \\
(n=42)\end{array}$ & \begin{tabular}{|c|} 
Sev-V.Sev \\
NPDR \\
+ PDR (n= 38)
\end{tabular} & $P$ value \\
\hline Duration of Diabetes & & & $4.84 \pm 6.32$ & $8.90 \pm 4.91$ & $15 \pm 5.71$ & $<0.0001$ \\
\hline $\mathrm{HbA}_{1 \mathrm{c}}$ & $5.90 \pm 0.45$ & $5.9 \pm 0.40$ & $8.28 \pm 1.89$ & $8.63 \pm 2.15$ & $9.06 \pm 1.5$ & $<0.0001$ \\
\hline Type of Treatment OHA & & & $36(90 \%)$ & $28(66.67 \%)$ & $20(50 \%)$ & \multirow{2}{*}{0.0005} \\
\hline Insulin & & & $4(10 \%)$ & $14(33.34 \%)$ & $20(50 \%)$ & \\
\hline
\end{tabular}

The mean duration of Diabetes was significantly more in subjects with higher grades of retinopathy ( $p<0.0001)$. It was $4.84 \pm 6.32$ years in No BDR group, $8.90 \pm 4.91$ years in group with mild-to-moderate NPDR and $15 \pm 5.71$ years in group with severe to very severe NPDR and PDR.

The HbA1c levels were significantly higher in those with higher grades of retinopathy. Mean $\mathrm{HbA} 1_{c}$ is $8.28 \pm 1.89$ in subjects with no background retinopathy group and $9.06 \pm$
1.5 in subjects with severe to very severe NPDR and PDR $(\mathrm{p}<0.0001)$.

The proportion of subjects on Insulin treatment significantly increases (p 0.0005) with increasing grade of Diabetic Retinopathy.

\begin{tabular}{|c|c|c|c|c|}
\hline & $\begin{array}{c}\text { Mean } \\
25(0 H) \text { D Level } \\
\end{array}$ & $P$ value & $\begin{array}{c}\text { Vitamin D } \\
\text { Insufficiency }\end{array}$ & $P$ value \\
\hline \multicolumn{5}{|c|}{ Serum Creatinine Levels } \\
\hline$<1$ & $25.04 \pm 6.71$ & \multirow{4}{*}{$<0.0001$} & \multirow{2}{*}{$96(154 / 192)$} & \multirow{4}{*}{0.005} \\
\hline $1-1.5$ & $22.57 \pm 7.26$ & & & \\
\hline $1.5-2$ & $18.75 \pm 8.96$ & & \multirow{2}{*}{$100(28 / 28)$} & \\
\hline$>2$ & $17.24 \pm 6.69$ & & & \\
\hline \multicolumn{5}{|c|}{ Hypertension } \\
\hline Present & $21.84 \pm 7.67$ & \multirow{2}{*}{0.0268} & $81.23(52 / 64)$ & \multirow[t]{2}{*}{0.589} \\
\hline Absent & $24.19 \pm 7.06$ & & $80.77(126 / 156)$ & \\
\hline \multicolumn{5}{|c|}{ Macrovascular Disease (CAD) } \\
\hline Present & $20 \pm 7.00$ & \multirow{3}{*}{$<0.001$} & $86.36(38 / 44)$ & \multirow{3}{*}{0.818} \\
\hline Absent & $24.15 \pm 7.19$ & & $79.54(140 / 176)$ & \\
\hline Absent & $24.15 \pm 7.19$ & & $79.54(140 / 176)$ & \\
\hline \multicolumn{5}{|c|}{ Table 3a. Co-morbidities and Vitamin D } \\
\hline
\end{tabular}

The mean Vitamin D levels decreases significantly ( $p<$ 0.0001 ) with the rise in mean serum creatinine levels. Also, vitamin D insufficiency was proportionally and significantly higher in the subjects with deranged serum creatinine levels.

The mean serum vitamin D levels were significantly lower in Hypertensives $(21.84 \pm 7.67 \mathrm{ng} / \mathrm{mL})$ than in nonhypertensives $(24.19 \pm 7.06 \mathrm{ng} / \mathrm{mL})$.

\begin{tabular}{|c|c|c|c|c|c|c|}
\hline & $\begin{array}{c}\text { No Ocular } \\
\text { DS, No DM } \\
(\mathrm{n}=58)\end{array}$ & $\begin{array}{c}\text { No DM with } \\
\text { Ocular DS } \\
(n=42)\end{array}$ & $\begin{array}{l}\text { No BDR } \\
(n=40)\end{array}$ & $\begin{array}{l}\text { Mild-Mod } \\
\text { NPDR } \\
(n=42)\end{array}$ & $\begin{array}{c}\text { Sev-V. Sev } \\
\text { NPDR + PDR } \\
(\mathrm{n}=38)\end{array}$ & P value \\
\hline Sr. Creatinine & $0.80 \pm 0.23$ & $0.99 \pm 0.20$ & $1.49 \pm 1.55$ & $1.10 \pm .39$ & $1.44 \pm 1.06$ & $<0.0001$ \\
\hline $\begin{array}{l}\text { Hypertension } \\
\text { Present }\end{array}$ & 4 & 24 & 6 & 14 & 16 & \multirow[t]{2}{*}{$<0.0001$} \\
\hline Absent & 54 & 18 & 34 & 28 & 22 & \\
\hline $\begin{array}{c}\text { Macrovascular Disease } \\
\text { Present }\end{array}$ & 8 & 10 & 14 & 16 & 22 & \multirow[t]{2}{*}{0.0001} \\
\hline Absent & 50 & 32 & 26 & 26 & 16 & \\
\hline
\end{tabular}

The above-mentioned table shows that mean creatinine levels were more in diabetics as compared to non-diabetic population. Among diabetics, the levels were significantly more with increasing grades of retinopathy.
The mean serum vitamin D levels were significantly lower in subjects with coronary artery disease $(20 \pm 7.00 \mathrm{ng} / \mathrm{mL})$ than those without it $(24.15 \pm 7.19 \mathrm{ng} / \mathrm{mL})$. 
in patients with mild-to-moderate NPDR and severe-to-very severe NPDR and PDR respectively.

The prevalence of macrovascular disease increases with increasing grade of retinopathy ( $p$ value 0.0001 ).

\section{DISCUSSION}

The mean vitamin $\mathrm{D}$ levels were higher (insignificantly- $\mathrm{p}$ $0.116)$ in females $(24.35 \pm 7.33 \mathrm{ng} / \mathrm{mL})$ as compared to males $(22.75 \pm 7.26 \mathrm{ng} / \mathrm{mL})$ - a finding similar to study by Payne et al, $2010^{9}$ and Joergensen et al $2010 .{ }^{10}$ There is no significant difference in the distribution of male and female subjects in the 5 study groups ( $\mathrm{p} 0.43$ ).

The mean vitamin D levels are significantly more $(\mathrm{p}<$ 0.0001 ) in patients with lesser BMI (mean vitamin D level of $28.23 \pm 3.24 \mathrm{ng} / \mathrm{mL}$ in $\mathrm{BMI}<20$ ) than those with higher BMI (mean vitamin D level of $19.73 \pm 8.15 \mathrm{ng} / \mathrm{mL}$ in $\mathrm{BMI}>30$ ). Payne et al $2011^{9}$ found similar result and stated higher the BMI lower the mean vitamin D levels. Obesity has been shown to affect vitamin D levels, possibly through vitamin D sequestration in fat deposits.

The BMI was significantly higher in those with higher grades of retinopathy. It is $23.52 \pm 3.70$ in no background retinopathy group and $26.37 \pm 3.43$ in those with severe to very severe NPDR and PDR $(\mathrm{p}<0.0001)$. Fawzia et al $2012^{11}$ reported average BMI of $33.1 \pm 1.1 \mathrm{~kg} / \mathrm{m}^{2}$ and $32.5 \pm 1.1$ $\mathrm{kg} / \mathrm{m}^{2}$ in patients with PDR and NPDR respectively and Juutilainen et al $2007^{9}$ found average BMI of $29.5 \pm 5.5 \mathrm{~kg} / \mathrm{m}^{2}$ and $31.3 \pm 5.5 \mathrm{~kg} / \mathrm{m}^{2}$ in patient with no background retinopathy and proliferative retinopathy respectively. Although in India among newly detected, diabetic lean diabetics are common but in present study majority of patients included already had diabetes for a long duration along with associated complications.

\section{Mean Vitamin D Levels and \% age Insufficiency in Vitamin $D$ among Diabetics and Non-Diabetics}

This study showed a significant and steady decline in mean serum vitamin D levels with increasing grades of Diabetic Retinopathy. Also, the proportion of diabetics with vitamin D insufficiency is significantly more with increasing grades of Retinopathy. Tukey-Kramer multiple comparison test shows significant difference in vitamin D in between group 1 with group 2, 3, 4 and 5 and group 2, 3 and 4 with group 5 $(\mathrm{p}<0.001)$. Payne et $\mathrm{al}^{9}$ found results comparable to this study.

Out of 120 Diabetics 80 developed Retinopathy, of which 78 were vitamin D insufficient. Vitamin D insufficiency was significantly associated with Diabetic Retinopathy ( $p$ 0.0023). Also, subjects with vitamin D insufficiency are at risk of having retinopathy 9.75 times that of vitamin D sufficient subjects (Odds Ratio 9.75; 95\% C.I. 1.96 to 48.46).

\section{Diabetic Profile and Vitamin D}

The lower level of mean vitamin $D$ in subjects with longer duration of Diabetes perhaps reflect that hyperglycaemia is implicated in vitamin D insufficiency as the glycaemic status worsens over time in most of the Diabetic patients.

The mean vitamin D levels were lower in subjects with higher HbA1c. Also, proportion of subjects with vitamin $\mathrm{D}$ insufficiency is more in those with higher $\mathrm{HbA} 1_{\mathrm{c}}$ Zoppinni et al $2013^{12}$ also found that Glycated Haemoglobin is inversely related to Serum Vitamin D Levels in Type 2 Diabetics.
The lower mean vitamin D levels in Diabetics on Insulin therapy again reflects the poor glycaemic control in these patients in addition to the longer duration of Diabetes.

\section{Diabetic Profile in the Study Groups}

The higher grades of retinopathy in patients with longer duration of Diabetes is attributed to the chronic alteration in retinal microvasculature as a result of metabolic disturbances.

The HbA1c levels were significantly higher in those with higher grades of retinopathy. These results were similar to study by Fawzia et al $2012^{13}$ (mean HbA1C levels was $9.0 \pm$ 10.9 years for PDR and $8.09 \pm 1.1$ for NPDR group). In the CURES eye study (Pradeepa et al 2010) ${ }^{14}$ found that for every $2 \%$ elevation of $\mathrm{HbA1C}$, the risk of DR increased by a factor of 1.7. These changes stem from poor glycaemic control causing retinal vascular damage.

The proportion of subjects on Insulin treatment significantly increases ( $p$ 0.0005) with increasing grade of Diabetic Retinopathy. The likelihood of Insulin treatment necessity increases with the duration of Diabetes due to the exhaustion of beta cells of pancreas and due to development of Diabetic Nephropathy, which precludes the use of oral hypoglycaemic agents.

\section{Co-morbidities and Vitamin D}

The mean Vitamin $D$ levels decreases significantly ( $p<0.0001$ ) with the rise in mean serum creatinine levels. This result is comparable to study of Payne et al, 2010.12

The vitamin D insufficiency is proportionally but insignificantly more in Hypertensive patients and vitamin D insufficiency does not pose any risk for development of Hypertension (odds ratio 1; 95\% C.I. 0.49 to 2.17).

Subjects with vitamin D insufficiency are at risk of developing Coronary Artery Disease 1.63 times that of vitamin D sufficient subjects (Odds Ratio 1.63; 95\% C.I. 0.64 to 4.15$)$.

\section{Co-morbidities in the 5 Study Groups}

The prevalence of Hypertension increase with increasing grade of retinopathy $(\mathrm{p}<0.0001)$, a result similar to that in study by Fawzia et al $2012^{14}$ (mean SBP/DBP was $142.2 \pm$ $4.4 / 91.69 \pm 2.9$ and $141 \pm 1.8 / 91.1 \pm 1.1 \mathrm{mmHg}$ in patients with NPDR and PDR respectively). Shrote et al $2015^{15}$ found significant relation between hypertension and retinopathy.

The prevalence of macrovascular disease increases with increasing grade of retinopathy ( $p$ value 0.0001 ). Rosenson et al $2011^{16}$ found that retinopathy was associated with approximately 1.7 fold increased risk for cardiovascular events and over two-fold increased risk for coronary events.

\section{CONCLUSION}

The most significant and outstanding finding of the study is that serum vitamin D level were significantly lower in Diabetics, specially in those with severe and very severe NPDR and PDR when compared to non-diabetics. Vitamin D play a protective role through its effects on glycaemic control and hypertension, both significant risk factors for the development and progression of diabetic retinopathy. ${ }^{2-4}$ It is possible that treating vitamin D insufficiency may lead to an improvement in blood sugar and blood pressure control, which could ultimately slow the progression of retinopathy. 
We, therefore, propose that all patients with type 2 diabetes mellitus, besides undergoing fundoscopic examination must be assessed for their vitamin D status at the point of diagnosis and supplemented appropriately if found insufficient so as to possibly prevent or even retard the progression of what has become the leading cause of blindness in the early adulthood till late ages.

\section{REFERENCES}

[1] Wild S, Roglic G, Green A, et al. Global prevalence of diabetes: estimates for the year 2000 and projections for 2030. Diabetes Care 2004;27(5):1047-53.

[2] Klein R, Klein BE, Moss SE. Relationship of glycemic control to diabetic microvascular complications in diabetes mellitus. Ann Intern Med 1996;124(1 Pt 2):90-6.

[3] UK Prospective Diabetes Study Group: Intensive blood-glucose control with sulphonylureas or insulin compared with conventional treatment and risk of complications in patients with type 2 diabetes (UKPDS 33). Lancet 1998;352(9131):837-53.

[4] The Accord Study Group, ACCORD Eye Study Group, Chew EY, et al. Effects of medical therapies on retinopathy progression in type 2 diabetes. $\mathrm{N}$ Engl J Med 2010;363(3):233-44.

[5] Holick MF. Vitamin D: importance in the prevention of cancers, type 1 diabetes, heart disease, and osteoporosis. Am J Clin Nutr 2004;79(3):362-71.

[6] Simpson S, Taylor B, Blizzard L, et al. Higher 25hydroxyvitamin $\mathrm{D}$ is associated with lower relapse risk in multiple sclerosis. Ann Neurol 2010;68(2):193203.

[7] Evatt ML, Delong MR, Khazai N, et al. Prevalence of vitamin D insufficiency in patients with Parkinson disease and alzheimer disease. Arch Neurol 2008;65(10):1348-52.
[8] Albert DM, Scheef EA, Wang S, et al. Calcitriol is a potent inhibitor of retinal neovascularization. Invest Ophthalmol Vis Sci 2007;48(5):2327-34.

[9] Payne JF, Ray R, Watson DG, et al. Vitamin D insufficiency in diabetic retinopathy. Endocrine Practice 2011;18(2):185-93.

[10] Joergensen C, Gall MA, Schmedes A, et al. Vitamin D levels and mortality in type 2 diabetes. Diabetes Care 2010;33(10):2238-43.

[11] Demerdash FE, Refaie W, Allakany R, et al. Diabetic retinopathy: a predictor of coronary artery disease. The Egyptian heart journal 2012;64(2):63-8.

[12] Targher G, Bertolini L, Zoppini G, et al. Retinopathy predicts cardiovascular mortality in type 2 diabetic men and women: response to Juutilainen et al. Diabetes care 2007;30(6):e51-2.

[13] Giacomo Z, Anna G, Giovanni T, et al. Glycated haemoglobin is inversely related to serum vitamin $\mathrm{D}$ levels in type 2 diabetic patients. PLoS ONE 2013;8(12):e82733.

[14] Pradeepa R, Anjana RM, Unnikrishnan R, et al. Risk factors for microvascular complications of diabetes among South Indian subjects with type 2 diabetes--the Chennai urban rural epidemiology study (CURES) eye study-5. Diabetes Technol Ther 2010;12(10):755-61.

[15] Shrote AP, Diagavane S. Clinical evaluation of correlation between diabetic retinopathy with modifiable, non-modifiable and other independent risk factors in tertiary set-up in central rural India. J Clin Diagn Res 2015;9(10):NC10-4.

[16] Rosenson RS, Fioretto P, Dodson PM. Does microvascular disease predict macrovascular events in type 2 diabetes? Atherosclerosis 2011;218(1):13-8. 